\title{
Análise crítica dos instrumentos de avaliação de cursos de graduação do Sinaes
}

\author{
Critical analysis of the undergraduate courses instruments of Sinaes
}

\author{
Julio César Godoy Bertolin ${ }^{*}$
}

\section{Resumo}

Há pouco tempo o Sistema Nacional de Avaliação da Educação Superior (Sinaes) completou uma década, tendo como uma de suas principais metas a melhoria da qualidade das instituições e dos cursos. Para alcançar esse importante objetivo, é fundamental que os instrumentos avaliativos empregados pelo sistema possuam adequação conceitual e técnica. Assim, após dez anos de operacionalização, cabe perguntar: especificamente no âmbito da avaliação dos cursos, os instrumentos empregados pelo Sinaes conseguem 'separar o joio do trigo'? Com o objetivo de contribuir no esclarecimento de tal questão, o presente artigo desenvolve, por meio de revisão da literatura e comparação de resultados, uma análise crítica dos instrumentos de avaliação de cursos de graduação do Sinaes. O estudo evidenciou que os instrumentos visitas in loco e Enade não possuem os atributos de validade e confiança.

Palavras-chave: Avaliação da educação superior. Instrumentos. Sinaes.

\section{Abstract}

Not long ago Sinaes completed a decade with the objective of improving the quality of the higher education. To achieve this goal, it is important that the evaluation tools and instruments have a good conceptual and technical adequacy. Thus, after ten years of implementation, it's worth asking particularly in the context of the undergraduate courses, if the Sinaes instruments are able to distinguish 'the good from the bad'. In order to contribute to the clarification of this issue, this article develops through the review of the literature and comparing the outputs, a critical analysis of courses instruments. The study showed that the in loco visits and Enade instruments may be neither valid nor reliable.

Keywords: Evaluation of higher education. Instruments. Sinaes.

Recebido em 15/05/2018 - Aprovado em 04/09/2018

http://dx.doi.org/10.5335/rep.v26i1.8401

Doutor em Educação e mestre em Ciência da Computação pela Universidade Federal do Rio Grande do Sul. Realizou pós-doutorado no Centro de Investigação de Políticas do Ensino Superior, em Porto, Portugal. É professor do Programa de Pós-Graduação em Educação da Universidade de Passo Fundo. Fez parte da Comissão Especial de Avaliação (CEA) do Ministério da Educação (MEC) que elaborou o Sinaes. Atuou como consultor da United Nations Educational, Scientific and Cultural Organization (UNESCO), do Programa das Nações Unidas para o Desenvolvimento (PNUD) e do MEC, no desenvolvimento de sistemas de avaliação da educação superior. E-mail: julio@upf.br 


\section{Introdução}

De maneira geral, pode-se dizer que avaliar implica a emissão de juízo de valor ou mérito sobre um objeto, um programa ou um sistema (SCRIVEN, 1991). Neste início de século XXI, provavelmente pela emergência da sociedade e economia do conhecimento que atribui à educação superior um papel vital para o desenvolvimento e o crescimento econômico das nações (UNESCO, 2010), cada vez mais, instituições acadêmicas têm se tornado objetos de análises e avaliações. No âmbito da educação superior, a avaliação tem sido adotada, em quase todos os países, por meio da implementação de políticas ou programas governamentais, que, muitas vezes, seguem orientações de organismos internacionais (UNESCO, 2010; ORGANISATION FOR ECONOMIC CO-OPERATION AND DEVELOPMENT, 2008). Gradativa e progressivamente, agências nacionais de acreditação ou mesmo comunidades de países (EUROPEAN ASSOCIATION FOR QUALITY ASSURANCE IN HIGHER EDUCATION, 2009) estabelecem critérios, procedimentos e diretrizes com vistas a garantia da qualidade, prestação de contas ou geração de informações para orientar as escolhas dos estudantes (AMARAL, 2007) nos emergentes (quase) mercados na educação superior (BERTOLIN, 2011).

No Brasil, a implementação da avaliação da educação superior em larga escala com abrangência nacional ocorreu, principalmente, a partir de 1995, por meio de dois diferentes instrumentos empregados pelo Instituto Nacional de Estudos e Pesquisas Educacionais Anísio Teixeira (Inep): exame aplicado aos concluintes dos cursos de graduação, o Exame Nacional de Cursos (ENC), conhecido como Provão; e visita in loco das comissões de especialistas, chamada de Avaliação das Condições de Oferta (ACO). ${ }^{1}$ Em 2004, um novo sistema, o Sistema Nacional de Avaliação da Educação Superior (Sinaes), foi implantado por força da Lei $\mathrm{n}^{\circ}$ 10.861/2004. Algumas mudanças importantes foram implementadas, tais como a autoavaliação das instituições e a ampliação da avaliação externa para o nível institucional. Dentre os principais objetivos do Sinaes, destacam-se a melhoria da qualidade, a orientação da expansão da oferta de vagas e a promoção do aprofundamento dos compromissos e responsabilidades sociais das instituições (BRASIL, 2004). O Sinaes possui três grandes pilares: (i) avaliação institucional; (ii) avaliação de cursos; e (iii) avaliação do desempenho dos estudantes. Esses pilares são atendidos pelos processos de avaliação in loco para os dois primeiros itens e complementados pela organização e avaliação interna de cada instituição de ensino superior. $\mathrm{O}$ terceiro item é atendido pela realização do Exame Nacional de Desempenho dos Estudantes (Enade). Nos anos subsequentes, no transcorrer da operacionalização do Sinaes, índices de desempenho foram criados a partir dos resultados das avaliações 
in loco das comissões de especialistas, como o Conceito de Curso (CC) e o Conceito Institucional (CI), e dos resultados do Enade, tais como o Conceito Preliminar de Curso (CPC) para os cursos e o Índice Geral de Cursos (IGC) para as instituições.

Não obstante algumas mudanças que tornaram a ideia original, amplamente formativa, numa avaliação híbrida entre formativa e somativa, estudos têm indicado que, conceitualmente, o Sinaes representou um avanço em relação à antiga avaliação baseada no Provão e na ACO (BERTOLIN, 2004; BARREYRO; ROTHEN, 2006). Entretanto, para além do debate da concepção, há escassez de literatura sobre a adequação ou não da operacionalização realizada e implementada pelo Sinaes. Não há dúvida de que para o Sinaes alcançar seus objetivos, como o de promover a melhoria da qualidade, é fundamental que os instrumentos da operacionalização possuam adequação conceitual e técnica. Ou seja, para que o Sinaes consiga separar "o joio do trigo", emitindo juízos distintos para cursos qualitativamente diferentes, faz-se necessário contar com instrumentos adequados. Assim, é fundamental se perguntar: os instrumentos do Sinaes possibilitam uma avaliação justa dos cursos de graduação? Será que os instrumentos do Sinaes geram informações válidas e confiáveis?

Investigar e analisar criticamente a qualidade e a adequação do Sinaes ainda é um desafio importante para a educação superior brasileira, visto que tal procedimento certamente contribuirá para melhorar o próprio sistema, para aumentar sua credibilidade e, por conseguinte, para orientar corretamente as políticas públicas de qualidade, equidade e expansão da educação superior. Dessa forma, considerando a importância da avaliação para promover a melhoria da qualidade da educação superior, bem como a relevância de se buscar respostas para as questões apresentadas, o presente artigo desenvolve uma análise crítica dos dois principais instrumentos do Sinaes que avaliam e consubstanciam os conceitos publicizados dos cursos de graduação: visitas in loco e Enade.

\section{A adequação de um instrumento de avaliação}

A elaboração de qualquer instrumento de avaliação e de medida, tanto para os fenômenos da natureza como para os sociais, requer atenção e cuidados, sem os quais não se poderá ter segurança em relação aos resultados a serem gerados. O sucesso de um instrumento de avaliação é alcançado quando ele consubstancia resultados merecedores de créditos, ou seja, um instrumento de medida pode ser considerado adequado no momento em que ele gera resultados confiáveis e válidos. ${ }^{2}$ A confiança está relacionada com a constância dos resultados quando um mesmo objeto é avaliado em mais de uma oportunidade ou, noutras palavras, re- 
fere-se à consistência ou estabilidade das "medidas" geradas. A validade, por sua vez, diz respeito à produção dos efeitos esperados, ou seja, ao grau em que, de fato, se "mede" o que realmente se pretende avaliar (DE ANDRADE MARTINS, 2006).

Ao definir meta-avaliação, ou seja, ao especificar o que é um processo para emissão de juízo de valor ou mérito sobre uma avaliação, Daniel L. Stufflebeam, fez referência a termos relacionados com validade e confiabilidade:

Meta avaliação é o processo de delinear, obter e aplicar informações descritivas e de julgamento sobre a utilidade, a viabilidade, a propriedade e a precisão de uma avaliação, bem como sobre a natureza sistemática, de confiabilidade, integridade, respeitabilidade e responsabilidade social para orientar a avaliação e revelar publicamente os seus pontos fortes e fracos (2001, p. 183).

Assim, a realização de uma análise crítica ${ }^{3}$ de instrumentos de avaliação, que é fundamental, visto que todo estudo avaliativo possui, em alguma medida, um viés tendencioso em função da inexorável influência de visões e valores, deve envolver uma investigação detalhada acerca da capacidade dos instrumentos gerarem resultados merecedores de crédito no que diz respeito ao cumprimento das funções para as quais foram criados.

Segundo a literatura, a análise de uma avaliação pode, se for formativa, ${ }^{4}$ melhorar um estudo antes de ele ser completamente inutilizado ou, se for somativa, ${ }^{5}$ pode aumentar a credibilidade dos resultados gerados (WORTHEN; SANDERS; FITZPATRICK, 1997). Especificamente no contexto do Sinaes, é importante evidenciar a avaliação formativa, por ser esta identificada como aquela que deveria pautar o desenvolvimento do sistema implantado em 2004. De acordo com Dias Sobrinho (2003), coordenador da Comissão Especial de Avaliação (CEA) do Ministério da Educação (MEC) do governo brasileiro, que elaborou a proposta inicial do Sinaes, a avaliação de natureza formativa é aquela que se desenvolve ao longo do processo avaliativo, por meio de um acompanhamento contínuo e sistemático, possibilitando a revisão e o aperfeiçoamento dos métodos e instrumentos, assim como a identificação de problemas e a utilização dos resultados.

Segundo Daniel L. Stufflebeam e Anthony J. Shinkfield, num processo de avaliação deve-se ter: "[...] muito cuidado não somente quando se recolhe as informações, que devem ser de qualidade, mas também quando se esclarece e estabelece uma base lógica que justifique as perspectivas de valoração utilizadas para interpretar os resultados" (1995, p. 20). Dessa forma, é plausível afirmar que os instrumentos de coleta de dados do Sinaes são fundamentais para o êxito das avaliações, visto que, sem a obtenção de dados e informações válidas e confiáveis sobre os cursos de graduação, a possibilidade da emissão de juízo de valor ou mérito adequada fica significativamente comprometida. Especificamente em relação 
às avaliações de cursos de graduação do Sinaes, o estudo sobre a adequação de seus dois principais instrumentos é fundamental para se poder emitir juízo de valor ou mérito sobre o sistema como um todo. Tais instrumentos, as visitas in loco realizadas pelas comissões de especialistas e o Enade aplicado aos alunos geram as principais informações para a regulação estatal ${ }^{6}$ e divulgam, para conhecimento da sociedade, a qualidade dos cursos de graduação da educação superior brasileira.

De certa forma, a partir de uma perspectiva sistêmica, pode-se interpretar que as visitas in loco avaliam as "entradas" e os "processos" por meio da verificação do corpo docente, da infraestrutura e da implementação do Projeto Pedagógico do Curso (PPC), enquanto o Enade avalia as "saídas" (ou produtos), na medida em que busca "medir" a aprendizagem dos alunos. Assim, com vistas a realizar uma análise crítica dos instrumentos de avaliação de cursos do Sinaes, que abordam tanto as dimensões de entradas e processos como as de saídas, a seguir, o presente trabalho desenvolve, por meio de revisão da literatura e comparações de resultados, estudos sobre (i) a utilidade e a confiabilidade dos indicadores do instrumento das visitas in loco, (ii) a capacidade do Enade de evidenciar a qualidade de um curso e (iii) a existência de coerência entre os resultados gerados pelos dois instrumentos - visitas in loco e Enade.

\section{Os indicadores das visitas in loco}

Nas visitas in loco para avaliação dos cursos de graduação, os membros das comissões de especialistas faziam uso, até meados do ano 2014, do Instrumento de Avaliação de Cursos de Graduação ${ }^{7}$ (IACG), preenchendo-o no formulário eletrônico do sistema informatizado e-MEC. ${ }^{8}$ A visita in loco, com base no IACG, subsidia a regulação estatal de cursos - autorização, reconhecimento e renovação de reconhecimento - nos graus de tecnólogo, licenciatura e bacharelado para ambas as modalidades: presencial e a distância. O IACG possui 80 indicadores, distribuídos em três dimensões: a) organização didático-pedagógica (36); b) corpo docente e tutorial (21); e c) infraestrutura (23). Alguns indicadores se aplicam especificamente a determinados cursos, dependendo das diretrizes curriculares, do grau ou da modalidade. Após a realização de entrevistas, reuniões, análises de documentos e dados e visitas às instalações das instituições, os membros das comissões de especialistas devem atribuir conceitos de 1 a 5 , em ordem crescente de excelência, ${ }^{9}$ para todos os indicadores das três dimensões. Cada indicador apresenta, predominantemente, um objeto de análise. O Conceito do Curso (CC) é calculado, pelo sistema e-MEC, com base na média aritmética ponderada dos conceitos das dimensões, ${ }^{10}$ os quais são resultados da média aritmética simples dos indicadores das respectivas dimensões (BRASIL, 2011). 
Instrumentos de avaliação da qualidade, como o IACG, são estruturados fundamentalmente por indicadores quantitativos e/ou qualitativos. Assim, uma das principais formas de análise de tais instrumentos ocorre por meio da validação do processo de geração dos seus indicadores, ou seja, de uma auditoria da qualidade de tais indicadores. Para se verificar a qualidade de um indicador, faz-se necessário o estabelecimento prévio de critérios e procedimentos padrões. Geralmente, um indicador é entendido como um elemento informativo, sobre um componente ou atributo do curso, orientado a servir de fundamento para se elaborar juízos sobre este. Porém, nem tudo que é avaliável em educação superior é mensurável, e, portanto, indicadores qualitativos são necessários para aspectos importantes do processo educacional.

Não obstante as diferenças de foco, são vastas na literatura as apresentações de características necessárias para que indicadores quantitativos e qualitativos sejam úteis e confiáveis, dentre as quais estão relevância e significância, imediatez, validade e confiabilidade, exequibilidade e perdurabilidade (BERTOLIN, 2007). Segundo Piotr Trzesniak (1998), entre as propriedades indispensáveis que qualquer indicador deve, a priori, necessariamente apresentar estão: (i) relevância retratar um aspecto importante ou crítico; (ii) gradação de intensidade - variar suficientemente no escopo de interesse; (iii) univocidade - retratar com clareza um único aspecto; (iv) padronização - basear-se num procedimento ou norma bem definida; e (v) rastreabilidade - possibilidade de recuperação de dados geradores. Apesar de formulação voltada para indicadores quantitativos, tais propriedades coadunam com grande parte das características apontadas na literatura como necessárias também aos indicadores qualitativos (TIRONI et al., 1991).

Em sua dissertação de mestrado, Aspectos contextuais e metodológicos da avaliação da qualidade da educação superior brasileira: uma análise dos indicadores utilizados pelos órgãos reguladores nos processos de avaliação dos cursos de graduação, Edcleide M. da Silva (2013) avaliou os indicadores do IACG. Foram selecionados seis indicadores, três qualitativos: (1) objetivos dos cursos, (2) conteúdos curriculares e (3) laboratórios didáticos especializados: serviços; e três quantitativos: (4) titulação de corpo docente, (5) produção científica, cultural, artística e tecnológica e (6) bibliografia básica, com vistas à verificação da existência das características a priori e desejáveis que todo indicador deve possuir, segundo o modelo teórico de Trzesniak (1998). Na amostragem utilizada com indicadores das três dimensões, o estudo apontou apenas a presença da propriedade de relevância em todos os indicadores (Quadro 1). As demais propriedades, gradação de intensidade, univocidade, padronização e rastreabilidade, não estavam presentes de forma inequívoca, pelo menos em um dos indicadores analisados. 
Quadro 1 - Presença de propriedades em indicadores do IACG

\begin{tabular}{|l|c|c|c|c|c|}
\hline \multicolumn{1}{|c|}{ Indicador } & Relevância & $\begin{array}{c}\text { Gradação de } \\
\text { intensidade }\end{array}$ & Univocidade & Padronização & Rastreabilidade \\
\hline $\begin{array}{l}\text { Objetivos do curso } \\
\text { Conteúdos } \\
\text { curriculares } \\
\text { Laboratórios didáticos } \\
\text { especializados: } \\
\text { serviços }\end{array}$ & $\mathbf{X}$ & $\mathbf{X}$ & & & \\
$\begin{array}{l}\text { Titulação do corpo } \\
\text { docente }\end{array}$ & $\mathbf{X}$ & $\mathbf{X}$ & $\mathbf{X}$ & $\mathbf{X}$ & $\mathbf{X}$ \\
$\begin{array}{l}\text { Produção científica, } \\
\text { cultural, artística e } \\
\text { tecnológica }\end{array}$ & $\mathbf{X}$ & $\mathbf{X}$ & $\mathbf{X}$ & $\mathbf{X}$ & \\
Bibliografia básica & $\mathbf{X}$ & & & & \\
\hline
\end{tabular}

Fonte: elaboração dos autores com base em Edcleide M. da Silva (2013).

Assim, não obstante a presença inerente de certo grau de subjetividade, o estudo desenvolvido por Edcleide M. da Silva sobre o IACG evidenciou que o instrumento teve problemas no momento da sua elaboração, especialmente na especificação e validação dos indicadores, visto que nem todos possuem as propriedades básicas de um bom indicador, em especial no que diz respeito a univocidade, padronização e rastreabilidade. Por conseguinte, parece adequado se considerar a possibilidade da inexistência de um referencial teórico consistente para a definição dos indicadores.

Um instrumento como o IACG, elaborado para ser referencial da regulação para mais de 30 mil cursos de graduação das diferentes instituições estatais e privadas de todo o Brasil, necessitaria possuir um consistente referencial teórico para a especificação de indicadores ou então deveriam ter sido submetidos a um processo prévio e rigoroso de testagem como validação antes da aplicação em larga escala. ${ }^{11}$ Entretanto, não é isso que o estudo demonstra. Dessa forma, é plausível dizer que o atributo validade do IACG, utilizado nas avaliações dos cursos de graduação durante as visitas in loco, pode ser questionado, visto que sem indicadores úteis e confiáveis, todo instrumento de avaliação pode gerar resultados distintos dos esperados. 


\section{Os resultados do Enade}

O Enade é o outro instrumento que o Sinaes emprega para avaliar cursos de graduação, com o objetivo principal de emitir juízo sobre:

[...] o desempenho dos estudantes em relação aos conteúdos programáticos previstos nas diretrizes curriculares do respectivo curso de graduação, suas habilidades para ajustamento às exigências decorrentes da evolução do conhecimento e suas competências para compreender temas exteriores ao âmbito específico de sua profissão, ligados à realidade brasileira e mundial e a outras áreas do conhecimento (BRASIL, 2004, não paginado).

Além das questões sobre os conteúdos específicos e de formação geral respondidas pelos alunos, o Enade também possui um questionário de impressões dos estudantes sobre a própria prova, um questionário socioeconômico para os estudantes e um questionário para os coordenadores de curso (BRASIL, 2012). A partir do Enade, são calculados índices, tais como o Conceito Enade, ${ }^{12}$ o CPC, ${ }^{13}$ para os cursos de graduação, e o IGC, ${ }^{14}$ para as instituições acadêmicas. Todos esses índices possuem como principal componente de ponderação a nota obtida pelos estudantes na prova do Enade. ${ }^{15}$

Tais índices, gerados pelo Inep e largamente divulgados pelos meios de comunicação, são interpretados pela sociedade e por governos e instituições como uma espécie de certificação da qualidade ou da não qualidade de cursos e instituições da educação superior. Entretanto, a utilização dos resultados dos desempenhos de alunos em exames para avaliar qualidade de escolas e instituições é polêmica. Pesquisas avaliativas em larga escala, como o Relatório Coleman da década de 1960 (BROOKE; SOARES, 2008), e reflexões teóricas, como o conceito de capital cultural de Pierre Bourdieu (1966), evidenciaram, há muito tempo, que o desempenho de alunos em exames decorre mais do fator "contexto socioeconômico e familiar" (background) dos envolvidos do que da diferença de qualidade entre as escolas ou o chamado efeito escola. ${ }^{16}$ De acordo com tais pesquisas, fazer uso exclusivo de informações sobre desempenho de alunos em exames para acreditar a qualidade de instituições ou cursos é uma temeridade. No âmbito da educação superior, os estudos sobre fatores determinantes do desempenho dos estudantes foram menos frequentes do que na educação básica. Não obstante, em países desenvolvidos já existe uma quantidade significativa de trabalhos que abordam a relação entre background e desempenho dos graduandos (PARK; KERR, 1990; ANDERSON; BENJAMIN; FUSS, 1994; SMITH; NAYLOR, 2001).

Especificamente em relação à educação superior brasileira, há trabalhos acadêmicos que começam a desvelar a pouca significância da qualidade ou do efeito do curso de graduação (efeito escola) no desempenho dos alunos nos exames na- 
cionais Provão e Enade. Na dissertação intitulada Enade 2006: determinantes do desempenho dos cursos de Ciências Contábeis, Emerson Santana de Souza (2008) buscou identificar algumas variáveis determinantes do desempenho dos cursos de Ciências Contábeis no Enade de 2006. Os resultados encontrados indicaram que o nível da formação dos estudantes antes do seu ingresso na educação superior é a variável de maior influência no desempenho dos cursos. Na sequência, em ordem decrescente, apareceram a escolaridade do pai, o esforço pessoal no curso e a renda familiar como as variáveis mais influentes de acordo com o modelo desenvolvido pelo estudo.

Outro trabalho desenvolvido nesse sentido foi a tese de doutorado de Marjorie Cristina Rocha da Silva (2011), Validade do Enade para avaliação da qualidade dos cursos: modelo de Rasch e multinível, que utilizou dados de 71.838 ingressantes e 58.428 concluintes do curso de Administração do Enade de 2006, além de informações sobre as instituições de ensino e o perfil socioeconômico dos respondentes. Os resultados encontrados demonstraram que, após o controle de algumas variáveis relacionadas ao perfil anterior ao ingresso na educação superior, tais como notas dos ingressantes, renda e formas de sustento e trabalho, somente $4 \%$ da variabilidade do desempenho dos concluintes pode ser creditada à instituição. $\mathrm{O}$ restante está relacionado às diferenças individuais entre os estudantes. Em síntese, o estudo demonstrou que existe pouca variabilidade para afirmar que o exame avalia a qualidade do curso.

Mais recentemente, a tese de doutorado de Nálbia de Araújo Santos (2012), sob o título Determinantes do desempenho acadêmico dos alunos dos cursos de Ciências Contábeis, analisou o efeito de características individuais e institucionais sobre o desempenho acadêmico dos estudantes dos cursos de Ciências Contábeis no Provão, nas edições de 2002 e 2003, e no Enade, de 2006 e 2009. Os principais resultados sugeriram associação significativa entre o desempenho dos estudantes concluintes nos exames de 2002, 2003 e 2006 com determinadas características próprias e da família, tais como gênero, horas de dedicação aos estudos, faixa de renda familiar, ter estudado o ensino médio em escolas públicas e certos insumos das instituições, como ter tido professores com domínio do conteúdo e que utilizaram como metodologia predominante aulas expositivas.

Além do demonstrado em tais trabalhos acadêmicos, o simples cálculo das médias obtidas por diferentes grupos socioeconômicos de graduandos do Enade reforça a importância dos contextos familiar, social, econômico e cultural no desempenho dos alunos. Nas edições do Enade dos anos 2007 e 2008, quanto melhor a condição socioeconômica do estudante, maior foi o valor agregado para os diferentes subgrupos de graduandos. A diferença das médias no conteúdo específico 
entre ingressantes e concluintes aumentou significativamente para as diferentes condições socioeconômicas dos estudantes, independentemente da categoria administrativa das instituições. Quanto maior a renda da família, quanto melhor a escolaridade da mãe (Tabela 1) e quanto melhor a qualidade da escola frequentada pelo aluno no ensino médio, maior a melhora de desempenho dos concluintes em relação aos ingressantes.

Tabela 1 - Melhora percentual da média no conteúdo específico dos concluintes em relação à média dos ingressantes por subgrupos de escolaridade da mãe - Enade 2007

\begin{tabular}{l|c|c|c|c|c|c}
\hline \multirow{2}{*}{$\begin{array}{c}\text { Indicador } \\
\text { social }\end{array}$} & \multicolumn{3}{|c|}{ Instituições privadas } & \multicolumn{3}{c}{ Instituições federais de educação superior } \\
\cline { 2 - 7 } & Ingressantes & Concluintes & Melhora \% & Ingressantes & Concluintes & Melhora \% \\
\hline Nenhuma & 31,24 & 36,27 & 16 & 33,07 & 40,12 & 21 \\
Até 4 $^{\circ}$ & 32,98 & 40,61 & 23 & 35,29 & 45,53 & 29 \\
Até 8 $^{\circ}$ & 32,45 & 42,69 & 32 & 36,56 & 46,57 & 27 \\
Médio & 32,02 & 44,05 & 38 & 35,24 & 48,72 & 38 \\
Superior & 31,91 & 46,17 & 45 & 35,75 & 53,14 & 49 \\
\hline
\end{tabular}

Fonte: elaboração dos autores com base em dados do Inep (BRASIL, 2012).

Portanto, coadunando com os primeiros estudos acadêmicos realizados sobre o Provão e o Enade, o exercício de cálculo das médias dos alunos nas edições 2007 e 2008 do exame aponta para o background como principal fator determinante no desempenho dos estudantes na educação superior brasileira e não para o fator escola (no caso da educação superior, fator curso de graduação), como deveria de ser para se poder divulgar o Conceito Enade e o próprio CPC como índices de qualidade dos cursos. Dessa forma, é plausível afirmar que o atributo de validade do Enade pode ser colocado em questão, visto que é temerário tomá-lo como fonte de informação para se emitir juízo de valor ou mérito sobre a qualidade dos cursos de graduação.

\section{A comparação entre CC e CPC}

Os dois principais instrumentos de avaliação externa do Sinaes, visitas in loco realizadas pelas comissões de especialistas e o Enade aplicado aos alunos, subsidiam a atribuição de conceitos (CC e CPC) para os cursos de graduação, ordenados em uma escala com cinco níveis. Independentemente de diferenças de objeto de análise (entradas e processos ou saídas) e de variabilidade metodológica na forma de cálculo, em ambos os conceitos, resultados inferiores a três denotam um curso com qualidade insuficiente. ${ }^{17}$ Por força normativa, os cursos que obtêm CPC insatisfatório a partir do Enade, em qualquer dos anos do ciclo avaliativo, devem protocolar pedido de renovação de reconhecimento, procedimento que resulta numa 
avaliação de visita in loco realizada por comissão de especialistas, o que, por conseguinte, possibilita que um mesmo curso passe por avaliação pelos dois diferentes instrumentos do Sinaes. ${ }^{18}$

De acordo com a sequência estabelecida para aplicação dos instrumentos de avaliação, primeiro, tem-se o Enade para todos os cursos e, segundo, a realização de visitas in loco por comissões de especialistas apenas para cursos com CPC insatisfatório, deduz-se que o sistema está estruturado de forma a avaliar a "saída" (aprendizagem dos alunos), para, posteriormente, em caso de necessidade, avaliar as "entradas" e o "processo" (corpo docente, infraestrutura e projeto pedagógico) dos cursos. Ao se realizar a comparação dos conceitos gerados para um mesmo curso disponíveis no sistema e-MEC, é possível observar que nem sempre a visita in loco e o Enade geram informações coerentes entre si para a geração dos conceitos CC e CPC. Numa amostragem de cinco conjuntos de cursos com diversidade de áreas do conhecimento, considerando Ciência da Computação, Direito, Medicina, Administração e Pedagogia, constata-se que o conceito estabelecido nas visitas in loco (CC) tende a ser superior ao conceito decorrente do Enade (CPC) para o mesmo curso (Tabela 2).

Tabela 2 - Comparação percentual de superioridade, igualdade ou inferioridade entre os conceitos CC e CPC nas avaliações realizadas para os mesmos cursos

\begin{tabular}{c|c|c|c|c|c}
\cline { 2 - 5 } & $\begin{array}{c}\text { Ciência da } \\
\text { Computação }\end{array}$ & Direito & Medicina & Administração & Pedagogia \\
\hline CC > CPC & $77 \%$ & $88 \%$ & $49 \%$ & $93 \%$ & $88 \%$ \\
CC = CPC & $22 \%$ & $11 \%$ & $40 \%$ & $6 \%$ & $12 \%$ \\
CC < CPC & $1 \%$ & $1 \%$ & $11 \%$ & $1 \%$ & $0 \%$ \\
\hline
\end{tabular}

Fonte: elaboração dos autores com base em dados do MEC (BRASIL, 2013).

$\mathrm{Na}$ amostragem selecionada, raramente o CPC de um curso é superior ao seu CC. Dentre os casos analisados, apesar de pequena, apenas nos cursos de Medicina se observa alguma possibilidade, aproximadamente uma em cada dez avaliações realizadas, de o conceito decorrente do instrumento Enade ser superior ao conceito subsidiado pela visita in loco. Nos demais cursos, tal condição é muito improvável. Em apenas 1\% dos casos para Ciência da Computação, Direito e Administração, e 0\% dos casos para Pedagogia, o CPC (Enade) foi superior ao CC (visita in loco). Tais números sugerem a geração de informações divergentes sobre os aspectos qualitativos pelos diferentes instrumentos para um mesmo curso.

No sistema e-MEC, na internet, no início do ano de 2013, estavam disponíveis para consulta, em relação aos cursos de Ciência da Computação, Direito, Medicina, Administração e Pedagogia, 6.083 resultados de avaliações externas, sendo 2.580 
por meio de CC e 3.508 por meio de CPC, ou seja, ambas as avaliações continham uma amostragem adequada de tal conjunto, visto que, no total, existiam aproximadamente sete mil desses cursos de graduação no país. As porcentagens de resultados que apontaram cursos com nível de qualidade insuficiente (conceito inferior a 3) eram significativamente diferentes entre os conceitos CC e CPC. Em média, pouco mais de $4 \%$ das avaliações que geram o $\mathrm{CC}$ (visita in loco) resultavam como indicativo de cursos com qualidade insuficiente. De outro modo, exatos 33\%, ou seja, uma em cada três avaliações divulgadas por meio do CPC, apontavam para cursos com qualidade insatisfatória (Tabela 3).

Tabela 3 - Percentual de avaliações com resultados de CC e CPC de qualidade insatisfatória

\begin{tabular}{c|c|c|c|c|c|c}
\hline Indicador & $\begin{array}{c}\text { Ciência da } \\
\text { Computação }\end{array}$ & Direito & Medicina & Administração & Pedagogia & Média \\
\hline CC & $11 \%$ & $2 \%$ & $2 \%$ & $2 \%$ & $5 \%$ & $4 \%$ \\
CPC & $24 \%$ & $31 \%$ & $20 \%$ & $40 \%$ & $50 \%$ & $33 \%$ \\
\hline
\end{tabular}

Fonte: elaboração dos autores com base em dados do MEC (BRASIL, 2013).

Assim, da mesma forma que no cotejamento realizado anteriormente, a comparação dos percentuais de resultados de avaliações com CC e CPC insatisfatórios também suscita considerações acerca da incongruência dos conceitos gerados. Consideradas as diferenças de enfoque, há que se ponderar que, como ambos os instrumentos - visitas in loco e Enade - subsidiam a geração de conceitos dentro de uma mesma escala (de 1 a 5) e com o mesmo corte na gradação para indicar um curso sem qualidade satisfatória (conceito inferior a 3), por óbvio, ambos os conceitos, CC e CPC, deveriam gerar resultados mais parecidos para os mesmos cursos. Entretanto, não é isso que se observa. Essa situação, muito provavelmente, gera leituras errôneas acerca da qualidade dos cursos e, por conseguinte, permite deduzir que ao menos um dos instrumentos pode ser contestado em relação ao atributo de confiança, visto que não apresenta constância dos resultados para um mesmo curso que é avaliado em mais de uma oportunidade.

\section{Conclusão}

Um sistema de avaliação deve possuir uma concepção teórica consistente para poder nortear o desenvolvimento de instrumentos confiáveis e válidos. Nesse sentido, é vasta, na literatura especializada, a descrição de modelos de avaliação para diferentes finalidades que citam diversas e variadas sistemáticas. Dentre os modelos de desenvolvimento de avaliação, podem-se destacar estudos baseados em objetivos, na experimentação, de orientação à decisão e centrados nos usuários. 
Apesar de não seguir um modelo pré-determinado, a concepção original do sistema não é um problema do Sinaes, entretanto, parece que o mesmo não se pode dizer dos instrumentos.

Com vistas a abordar um aspecto ainda pouco estudado do Sinaes, qual seja a (in)adequação dos instrumentos do sistema, neste trabalho, buscou-se verificar a utilidade e a confiabilidade dos indicadores do instrumento das visitas in loco, a capacidade do Enade de evidenciar a qualidade de um curso e a existência de coerência entre os resultados gerados pelos dois instrumentos. Nesse sentido, a análise crítica desenvolvida acerca dos principais instrumentos de avaliação de cursos nas versões em uso no momento em que o sistema completava 10 anos evidenciou, por meio de revisão da literatura e comparações de resultados, que não é possível se dizer, com relativa margem de segurança, que os importantes atributos de validade e confiança estão presentes nas visitas in loco e no Enade.

Portanto, para além do problema largamente discutido na literatura do desvirtuamento da concepção original do Sinaes de avaliação formativa para uma avaliação preponderantemente somativa, a análise critica realizada no presente trabalho evidenciou que os instrumentos utilizados muito provavelmente não estão conseguindo separar "o joio do trigo" no universo dos cursos de graduação brasileiros. Portanto, parece adequado considerar que os instrumentos visitas in loco - com o seu IACG - e Enade - com o seu CPC - precisam ser revisados estruturalmente, no sentido de que adquiram os atributos de validade e confiança para, com isso, viabilizarem um processo de avaliação mais justo e preciso e, por conseguinte, poderem contribuir efetivamente com a melhoria das políticas de qualidade da educação superior brasileira.

\section{Notas}

1 No ano de 2001, a ACO passou a ser denominada de Avaliação das Condições de Ensino (ACE) (POLIDORI, 2009).

2 Os autores são praticamente unânimes em apontar dois critérios fundamentais de um bom instrumento de avaliação e/ou medida: validade e confiança. No contexto de pesquisas quantitativas, existem alguns testes rigorosos, baseados em técnicas estatísticas (ex.: Alfa de Cronbach, Coeficiente Kappa, Análise fatorial, Bland \& Altman), que buscam medir a validade e a confiabilidade de um instrumento de avaliação. Nesse estudo, entretanto, considerando que, no universo social e sob uma perspectiva qualitativa, nem sempre é possível se alcançar exatidão das avaliações (DE ANDRADE MARTINS, 2006), os termos validade e confiabilidade estão relacionados às ideias gerais de produção de efeitos esperados e consistência de resultados.

3 A ideia de análise crítica, geralmente, envolve o estudo minucioso de um projeto, produto ou processo, dividindo o objeto de análise em partes menores, com vistas a uma melhor compreensão do todo e a uma identificação de problemas para solução.

4 No contexto deste artigo, entende-se por avaliação formativa aquela com foco no processo do objeto de análise e que possui como destinatários dos resultados todos os sujeitos envolvidos. Assim, a avaliação formativa deve levar a decisões sobre o desenvolvimento, a modificação ou a revisão do curso e/ou programa avaliado. 
5 No contexto deste artigo, entende-se por avaliação somativa aquela com foco nos resultados do objeto de análise e que possui como destinatários dos resultados apenas os utentes ou financiadores envolvidos. Logo, a avaliação somativa deve levar a decisões sobre a continuidade, o encerramento ou a ampliação do curso e/ou programa avaliado.

6 A regulação estatal refere-se aos processos regulatórios de autorização, reconhecimento, renovação de reconhecimento de cursos de graduação e de credenciamento e recredenciamento de instituição de educação superior.

7 Trata-se de instrumento único (matricial para todos os atos autorizativos) utilizado para todos os cursos de graduação, em observância ao disposto na Lei no 10.861 , de 14 de abril de 2004; ao Decreto oㅜ 5.773 , de 09 de maio de 2006, que define como competência do Inep elaborar os instrumentos de avaliação; e à Portaria Normativa $\mathrm{n}^{\mathrm{0}} 40$, de 12 de dezembro de 2007, consolidada e republicada em dezembro de 2010, que atribui ao DAES/Inep as decisões sobre os procedimentos de avaliação. Este instrumento já passou por várias revisões sendo que a última ocorreu em abril de 2016.

8 O e-MEC é o sistema de tramitação eletrônica dos processos de regulação das instituições de ensino de superior e dos cursos de graduação instituído por meio da Portaria Normativa no 40/2007.

9 A orientação para atribuição dos conceitos segue, no geral, os seguintes critérios: 1 (um) quando os critérios de análise do indicador avaliado configuram um conceito NÃO ATENDE, 2 (dois) quando os critérios de análise do indicador avaliado configuram um conceito INSUFICIENTE, 3 (três) quando os critérios de análise do indicador avaliado configuram um conceito SUFICIENTE, 4 (quatro) quando os critérios de análise do indicador avaliado configuram um conceito MUITO BOM/MUITO BEM e 5 (cinco) quando os critérios de análise do indicador avaliado configuram um conceito EXCELENTE.

${ }^{10}$ Os pesos de cada dimensão podem mudar dependendo do ato regulatório em questão. No instrumento disponibilizado no site do Inep em junho de 2015, por exemplo, para autorização de curso, os pesos eram, respectivamente, $30 \%, 30 \%$ e $40 \%$ para as dimensões 1 - organização didático-pedagógica, 2 - corpo docente e tutorial e 3 - infraestrutura, e, no caso de reconhecimento ou renovação de reconhecimento de curso, os pesos eram, respectivamente, de $40 \%, 30 \%$ e $30 \%$.

${ }_{11}$ Nesse sentido, segundo informações obtidas com o pessoal do Inep no ano de 2014, naquele momento, estava sendo realizado um estudo inicial de validação dos indicadores pelo setor de Tecnologia e Informação do instituto e a comissão designada para aprimorar o instrumento em questão encontra-se envolvida no processo de revisão técnica.

${ }^{12}$ O Conceito Enade é calculado para cada curso, tendo como unidade de observação um curso de uma instituição, num município e numa área de avaliação. O Conceito Enade do curso consiste na média ponderada da nota padronizada dos concluintes na formação geral e no componente específico. A parte referente à formação geral contribui com $25 \%$ da nota final, enquanto a referente ao componente específico contribui com $75 \%$. O conceito é apresentado em cinco categorias ( 1 a 5 ), sendo 1 o resultado mais baixo e 5 o melhor resultado possível (BRASIL, 2012).

${ }^{13}$ O CPC é calculado para cada curso avaliado, combinando diversas medidas, tais como a nota dos concluintes no Enade, o indicador IDD, a nota dos ingressantes no Enade, a titulação e o regime de trabalho dos professores, os recursos pedagógicos e a infraestrutura (BRASIL, 2012).

${ }^{14}$ O IGC é uma média ponderada dos conceitos dos cursos de graduação (CPC) e, no caso de existência, dos programas de pós-graduação (Coordenação de Aperfeiçoamento de Pessoal de Nível Superior - Capes) da instituição. Para ponderar os conceitos, utiliza-se a distribuição dos alunos da instituição entre os diferentes níveis de ensino - graduação, mestrado e doutorado. Para a ponderação das matrículas de graduação, são utilizados os dados do Censo da Educação Superior (BRASIL, 2012).

${ }^{15}$ Apesar de o CPC, além da nota dos alunos no exame, contemplar outros aspectos do curso (ex.: titulação e regime de trabalho docente, recursos pedagógicos e infraestrutura), as variáveis decorrentes da nota no Enade têm mantido preponderância para a composição do conceito final. Em 2007, 70\% da composição do CPC se originava no desempenho dos alunos no Enade e, em 2008, tal participação estava fixada em 60\%. O IDD, também considerado no CPC, que poderia minimizar o impacto do perfil do aluno no conceito dos cursos tem sido questionado metodologicamente (BITTENCOURT et al., 2008). Em 2011, houve uma revisão desses percentuais e ficou 55\% para Nota do Indicador de Diferença entre os Desempenhos Observado e Esperado (NIDD) mais a Nota do Concluinte (NC), e $45 \%$ para os demais insumos (NPM, NPD, NPR, NF e NO) (Nota Técnica № 029, de 15 de outubro de 2012 - MEC/Inep/DAES). Em 2014, os percentuais ficaram com 55\% para Nota do Indicador de Diferença entre os Desempenhos Observado e Esperado (NIDD) e 
a Nota do Concluinte (NC), 15\% para Percepção discente sobre o processo formativo, dividido nos insumos - NO, NF, NA - e 30\% para Corpo Docente, considerados os insumos NM, ND, NR (BRASIL, 2015).

${ }^{16}$ A literatura que aborda os fatores associados ao desempenho dos alunos segmenta as variáveis determinantes em dois principais grupos, chamados efeito escola e background do estudante. Geralmente, a discussão central está relacionada ao poder de impacto de cada grupo no desempenho dos alunos. O efeito escola considera os atributos relacionados ao ambiente escolar, tais como infraestrutura física, recursos e ferramentas educacionais, projeto pedagógico, gestão e corpo docente. O background inclui, fundamentalmente, os contextos familiar, social, econômico e cultural dos alunos.

${ }^{17}$ No âmbito do processo regulatório, realizado atualmente pela Secretaria de Regulação e Supervisão da Educação Superior (Seres), conceitos insuficientes (1 e 2) indicam a não autorização, o não reconhecimento ou a não renovação de reconhecimento do curso avaliado.

${ }^{18}$ Outra situação em que um curso pode ser objeto de avaliação por ambos os instrumentos do Sinaes, visitas in loco e Enade, ocorre no caso de faculdades que recebem visitas com vistas à autorização para criar um curso e, na sequência, seus alunos realizam o Enade.

\section{Referências}

AMARAL, Alberto (Org.). Políticas do ensino superior: quatro temas em debate. Lisboa: Conselho Nacional de Educação, 2007.

ANDERSON, Gordon; BENJAMIN, Dwayne; FUSS, Melvyn A. The determinants of success in university introductory economics courses. The Journal of Economic Education, Oxfordshire, UK, v. 25, n. 2, p. 99-119, 1994.

BARREYRO, G. B.; ROTHEN, J. C. "Sinaes" contraditórios: considerações sobre a elaboração e implantação do Sistema Nacional de Avaliação da Educação Superior. Educação e Sociedade, Campinas, v. 27, n. 96, Edição Especial, p. 955-977, out. 2006.

BERTOLIN, Julio C. G. A transformação do Sinaes: da proposta emancipatória à Lei híbrida. Avaliação, Campinas, v. 9, n. 4, p. 67-76, 2004.

Avaliação da qualidade do Sistema de Educação Superior Brasileiro em tempos de mercantilização - período 1994-2003. 2007. Tese (Doutorado em Educação) - Universidade Federal do Rio Grande do Sul, Porto Alegre, 2007.

Os quase-mercados na educação superior: dos improváveis mercados perfeitamente competitivos à imprescindível regulação do Estado. Educação e Pesquisa, São Paulo, v. 37, n. 2, p. 237-248, 2011.

BITTENCOURT, H. R. et al. Uma análise da relação entre os conceitos Enade e IDD. Estudos em Avaliação Educacional, São Paulo, v. 19, p. 247-262, 2008.

BOURDIEU, Pierre. L'écoleconservatrice. Les inégalitésdevantl'écoleel la culture. Revuefrançaise de Sociologie, Paris, v. 7, p. 325-347, 1966.

BRASIL. Lei nº 10.861, de 14 de abril de 2004. Brasília, DF: Presidência da República, 2004.

Instituto Nacional de Estudos e Pesquisas Educacionais Anísio Teixeira. Enade. 2012.

Disponível em: <http://portal.inep.gov.br/web/guest/enade>. Acesso em: 20 ago. 2012. 
Instituto Nacional de Estudos e Pesquisas Educacionais Anísio Teixeira. Avaliação dos Cursos de Graduação. 2011. Disponível em: <http://portal.inep.gov.br/superior-condicoesdeensino-manuais>. Acesso em: 11 jul. 2013.

Instituto Nacional de Estudos e Pesquisas Educacionais Anísio Teixeira. Nota Técnica $n^{\circ} 58$ - Cálculo do Conceito Preliminar de Curso 2014. Brasília, DF: Inep, 2015. Disponível em: $<$ http://www.proen.ifpa.edu.br/documentos-1/eventos-proen/capacitacao-de-coordenadores-de-cursos-tecnicos-e-de-graduacao/legislacao-basica-cd/1372-nota-tecnica-daes-n582015-calculo-do-cpc2014/file>. Acesso em: 08 jul. 2016.

Ministério da Educação. Sistema e-MEC. 2013. Disponível em: <http://emec.mec.gov. br/>. Acesso em: 15 jan. 2013.

BROOKE, Nigel; SOARES, José Francisco. Pesquisa em eficácia escolar: origem e trajetórias. Belo Horizonte: Editora UFMG, 2008.

DE ANDRADE MARTINS, Gilberto. Sobre confiabilidade e validade. Revista Brasileira de Gestão de Negócios, São Paulo, v. 8, n. 20, p. 1-12, 2006.

DIAS SOBRINHO, José. Avaliação: políticas educacionais e reformas da educação superior. São Paulo: Cortez, 2003.

EUROPEAN ASSOCIATION FOR QUALITY ASSURANCE IN HIGHER EDUCATION. ENQA report on Standards and Guidelines for Quality Assurance in the European Higher Education Area. 3. ed. Helsinki, Finland: ENQA, 2009.

ORGANISATION FOR ECONOMIC CO-OPERATION AND DEVELOPMENT. Tertiary Education for the Knowledge Society. Volume 1. Special Features: governance, funding, quality. Paris: OECD Publications, 2008.

PARK, Kang H.; KERR, Peter M. Determinants of academic performance: a multinomial logit approach. The Journal of Economic Education, Oxfordshire, UK, v. 21, n. 2, p. 101-111, 1990.

POLIDORI, Marlis M. Políticas de avaliação da educação superior brasileira: Provão, Sinaes, IDD, CPC, IGC e... outros índices. Avaliação, Campinas; Sorocaba, SP, v. 14, n. 2, p. 439-452, jul. 2009.

SANTOS, Nálbia de Araújo. Determinantes do desempenho acadêmico dos alunos dos cursos de Ciências Contábeis. 2012. 248 f. Tese (Doutorado em Ciências Contábeis) - Universidade de São Paulo, São Paulo, 2012.

SCRIVEN, Michael. Evaluation thesaurus. London: Sage, 1991.

SILVA, Edcleide Maria da. Aspectos contextuais e metodológicos da avaliação da qualidade da educação superior brasileira: uma análise dos indicadores utilizados pelos órgãos reguladores nos processos de avaliação dos cursos de graduação. 2013. Dissertação (Mestrado Profissional em Gestão Pública para o Desenvolvimento do Nordeste) - Universidade Federal de Pernambuco, Recife, 2013.

SILVA, Marjorie Cristina Rocha da. Validade do Enade para avaliação da qualidade dos cursos: modelo de Rasch e multinível. 2011. 221 f. Tese (Doutorado em Psicologia) - Universidade São Francisco, São Paulo, 2011. 
SMITH, Jeremy; NAYLOR, Robin. Determinants of degree performance in UK universities: a statistical analysis of the 1993 student cohort. Oxford Bulletin of Economics and Statistics, Oxford, UK, v. 63, n. 1, p. 29-60, 2001.

SOUZA, Emerson Santana de. Enade 2006: determinantes do desempenho dos cursos de Ciências Contábeis. 2008. 96 f. Dissertação (Mestrado em Ciências Contábeis) - Programa Multi-institucional e Inter-regional de Pós-Graduação em Ciências Contábeis, UnB, UFPB e UFRN, Brasília, 2008.

STUFFLEBEAM, Daniel L. The meta evaluation imperative. American Journal of Evaluation, Washington, v. 22, n. 2, p. 183-209, 2001.

STUFFLEBEAM, Daniel L.; SHINKFIELD, Anthony J. Evaluación sistemática: guia teórica y práctica. Barcelona: Paidós Ibérica, 1995.

TIRONI, L. F. et al. Critérios para a geração de indicadores de qualidade e produtividade no serviço público. Texto para discussão no. 238. Brasília: Ipea/MEFP, 1991.

TRZESNIAK, Piotr. Indicadores quantitativos. Reflexões que antecedem seu estabelecimento. Ciência da Informação, Brasília, DF, v. 27, n. 2, p. 159-164, maio/ago, 1998.

UNITED NATIONS EDUCATIONAL, SCIENTIFIC AND CULTURAL ORGANIZATION (UNESCO). 2009 World Conference on Higher Education: The New Dynamics of Higher Education and Research for Societal Change and Development. Paris: UNESCO, 2010.

WORTHEN, B. R.; SANDERS, J. R.; FITZPATRICK, J. L. Program evaluation: alternative approaches and practical guidelines. 2. ed. White Plains, NY: Longman Publishers, 1997. 